\title{
Measurement of indoor air quality parameters in daycare centres in Kuala Lumpur Malaysia
}

\begin{abstract}
This paper focuses on the monitoring of indoor air quality parameters, namely: indoor temperature, humidity, velocity, particulate matter, carbon monoxide and carbon dioxide in day care centres. This study selected 15 day care centres located in Kuala Lumpur, Malaysia. These day care centres were categorized as follows: (1) day care centers near an industrial area, (2) day care centers near a main road, and (3) day care centers in a residential area. The obtained data showed that the values for the indoor air quality parameters in all day care centres were still well below the recommended value according to the Department of Safety and Health, Malaysia. The day care centers near an industrial area had the highest value of carbon monoxide, and carbon dioxide as compared to the day care centers near a main road and the day care centers in a residential area. The average concentrations of carbon monoxide, and carbon dioxide in the day care centers near an industrial area were $3.67 \mathrm{ppm}$ and $801.56 \mathrm{ppm}$ respectively. Meanwhile, the carbon monoxide, and carbon dioxide in the day care centers near a main road area and the day care centers in a residential area were 3.13 ppm, 768.22 ppm, $2.92 \mathrm{ppm}$ and 733.70 ppm, respectively.
\end{abstract}

Keyword: CO; Daycare; Indoor air quality; Schools 